\title{
Programme for Lifestyle, Activity \& Nutrition (PLAN): an effective and feasible inter-disciplinary group weight-management approach in the primary care setting
}

\author{
C. Diettrich ${ }^{1}$, S. Browne ${ }^{1}$, E. Dunphy ${ }^{2}$ and C. Glennon ${ }^{1}$ \\ ${ }^{1}$ Community Nutrition and Dietetic Service, Health Service Executive Dublin Mid-Leinster, Unit 25 Kilminchy Village, \\ Dublin Road, Portlaoise, Co. Laois, Republic of Ireland and ${ }^{2}$ Department of Research \& Clinical Audit, Health Service \\ Executive Dublin Mid Leinster, Block 4, Central Business Park, Clonminch, Tullamore, Co. Offaly, Republic of Ireland
}

Currently, $57 \%$ of Irish adults are either overweight or obese, while the indirect cost of obesity in Ireland is estimated at $€ 0.4 \times 10^{9}$ per year ${ }^{(1)}$. There is a pressing demand for effective and feasible interventions in the primary care setting to deal, on a local scale, with the obesity epidemic, as recommended by the National Taskforce on Obesity (2005) ${ }^{(1)}$. Approximately $12 \%$ of all patients referred to the Midlands Community Dietetic Service at the time of study were seen primarily for overweight or obesity. The aim of the present study was to develop a group weight-management approach in primary care and evaluate it by assessing attrition rate and weight loss and quality of life (QOL) changes achieved by participants and satisfaction among health professionals involved.

The inter-disciplinary content of the PLAN group programme was developed by community dietitians (CD) and physiotherapists. The healthy eating and activity messages were central to the learning aspect of the programme, whilst practical strategies for goal setting facilitated clients in implementing these messages at home. Participants initially had a BMI of $>25 \mathrm{~kg} / \mathrm{m}^{2}$ and no diagnosis of diabetes. Seventy adults attended the 6-week interdisciplinary weight-management programme facilitated by a CD (six sessions) and a physiotherapist (activity slot in three sessions) in two primary care team sites in the Midlands region of Ireland (September 2006-September 2007).

The participants were aged between 18 to 80 years. All participants, of which the majority were female $(77 \%, n=54)$ completed QOL questionnaires in week 1 and 6 of the programme. For this purpose, the health survey SF-12(2) was adapted for the client group. Health professionals' satisfaction was assessed via a focus group conducted by a Health Service Executive research officer at the end of the study period. The Table shows anthropometric measurements.

The direct contact time provided to seventy clients over 1 year was $61.5 \mathrm{~h}$. Each client attending the group received an average of five contact hours with the dietitian. The attrition rate for the programme after week 1 was $19 \%$. Ten clients $(15 \%)$ attended all 6 weeks of the programme and twenty-three clients $(35 \%)$ attended the programme on week 6.

Table. BMI and waist circumference (WC) before and after the PLAN group programme

\begin{tabular}{|c|c|c|c|c|c|c|c|c|c|}
\hline \multicolumn{5}{|c|}{ BMI $\left(\mathrm{kg} / \mathrm{m}^{2}\right)$} & \multicolumn{5}{|c|}{$\mathrm{WC}(\mathrm{cm})$} \\
\hline \multicolumn{2}{|c|}{ Week $1(n 65)$} & \multicolumn{2}{|c|}{ Final week attended $\dagger(n$ 31) } & \multirow[b]{2}{*}{$Z-2.98$} & \multicolumn{2}{|c|}{ Week $1(n$ 69) } & \multicolumn{2}{|c|}{ Final week attended $\dagger(n$ 22) } & \multirow[b]{2}{*}{$Z-3.77$} \\
\hline Median & Range & Median & Range & & Mean & Range & Mean & Range & \\
\hline 38.5 & $26.7-67.4$ & 36.2 & $25.0-57.1$ & $P<0.05^{*}$ & 120 & $90-157$ & 112 & $84-133$ & $P<0.05^{*}$ \\
\hline
\end{tabular}

*Wilcoxon sign ranks test. †Participants who attended until week 4,5 or 6 included.

QOL questionnaires completed before ( $n$ 64) and after the programme ( $n$ 28) show that QOL aspects (e.g. mood, body image) increased by an average of $36 \%$. The health professionals felt the diet and activity knowledge imparted and topics covered in the group programme were more diverse than in an individual consultation. Also, the group sessions were more interactive and there was more time available with the health professionals than offered in a typical individual consultation.

The PLAN programme was effective in achieving significant BMI and WC changes in the short term as well as positive changes in QOL for participants. The interdisciplinary group approach represents a feasible option for the management of overweight and obese patients in the primary care setting.

1. Department of Health and Children (2005) Obesity the Policy Challenges. The Report of the National Taskforce on Obesity. Dublin: The Stationery Office.

2. The International Quality of Life Assessment Project (1994) SF-12 Health Survey. www.iqola.org [accessed August 2006]. 